\title{
Detection of directivity in seismic site response from microtremor spectral analysis
}

\author{
V. Del Gaudio ${ }^{1}$, S. Coccia ${ }^{1}$, J. Wasowski ${ }^{2}$, M. R. Gallipoli ${ }^{3}$, and M. Mucciarelli ${ }^{4}$ \\ ${ }^{1}$ Dipartimento di Geologia e Geofisica, Università degli Studi di Bari, Italy \\ ${ }^{2}$ Istituto di Ricerca per la Protezione Idrogeologica, Consiglio Nazionale delle Ricerche, Bari, Italy \\ ${ }^{3}$ Istituto di Metodologie per le Analisi Ambientale, Consiglio Nazionale delle Ricerche, Tito Scalo, Potenza, Italy \\ ${ }^{4}$ Dipartimento di Strutture, Geotecnica, Geologia Applicata all'Ingegneria, Università degli Studi della Basilicata, \\ Potenza, Italy
}

Received: 27 February 2008 - Revised: 16 June 2008 - Accepted: 25 June 2008 - Published: 25 July 2008

\begin{abstract}
Recent observations have shown that slope response to seismic shaking can be characterised by directional variations of a factor of 2-3 or larger, with maxima oriented along local topography features (e.g. maximum slope direction). This phenomenon appears influenced by slope material properties and has occasionally been detected on landslide-prone slopes, where a down-slope directed amplification could enhance susceptibility to seismically-induced landsliding. The exact conditions for the occurrence of directional amplification remain still unclear and the implementation of investigation techniques capable to reveal the presence of such phenomena is desirable. To this purpose we tested the applicability of a method commonly used to evaluate site resonance properties (Horizontal to Vertical Noise Ratio - HVNR or Nakamura's method) as reconnaissance technique for the identification of site response directivity. Measurements of the azimuthal variation of $\mathrm{H} / \mathrm{V}$ spectral ratios (i.e. between horizontal and vertical component) of ambient microtremors were conducted in a landslide-prone study area of central Italy where a local accelerometric network had previously provided evidence of directivity phenomena on some slopes. The test results were compared with average $\mathrm{H} / \mathrm{V}$ spectral ratios obtained for low-to-moderate earthquakes recorded by the accelerometric stations. In general, noise and seismic recordings provided different amplitudes of spectral ratios at similar frequencies, likely because of differences in signal and instrument characteristics. Nevertheless, both kinds of recordings showed that at sites affected by site response directivity major $\mathrm{H} / \mathrm{V}$ peaks have orientations consistent (within $20^{\circ}-30^{\circ}$ ) with the direction of maximum shaking energy. Therefore, HVNR appears to be
\end{abstract}

Correspondence to: V. Del Gaudio (delga@geo.uniba.it) a promising technique for identifying seismic response directivity. Furthermore, in a comparative test conducted on a slope mantled in part by a deep-seated landslide we detected spectral peaks with orientations close to the maximum slope direction, whereas no evidence of directivity was found outside the slide boundaries. This indicates the influence of the landslide body on seismic response directivity.

\section{Introduction}

In the last two decades some workers (Bonamassa and Vidale, 1991; Vidale et al., 1991; Spudich et al., 1996; Xu et al., 1996; Martino et al., 2006) have reported cases of notable directional variations of seismic site response under different geological and topographical conditions. Our recent studies provided new evidence of this phenomenon (Del Gaudio and Wasowski, 2007). In particular, we analysed the directional variation of shaking energy in several earthquakes of low to moderate magnitude recorded by accelerometric stations located in eight hillslope sites of central Italy. For four of these sites shaking maxima were found in an almost constant direction, regardless the back-azimuth of the epicentres of the recorded events. The maxima of shaking energy were on average $2-3$ times as high as orthogonally directed minima and turned out oriented in directions close to that of locally prominent topographic features (i.e. maximum slope or steep scarp rim). Furthermore, preliminary accelerometer monitoring results from three different landslide-prone slopes in southern Italy indicated the presence of directional effects with maxima oriented along the general direction of slope movements (Gallipoli and Mucciarelli, 2007).

The analysis presented by Del Gaudio and Wasowski (2007) suggests that these phenomena are not caused by a purely topographic effect. Indeed, a fundamental role

Published by Copernicus Publications on behalf of the European Geosciences Union. 
seems to be played by anisotropies in slope material properties, which, in different settings, can be either induced by factors controlling also the topographic relief (e.g. tectonics) or directly controlled by the topography (e.g. as effect of gravity-driven mass movements).

The recognition of a pronounced directivity in site response is an important factor to be considered in local hazard evaluations and in building code applications. Furthermore, site response directivity can be relevant in enhancing susceptibility of slopes to earthquake induced failures considering that in most of the observed cases the direction of maximum shaking resulted close to that of the maximum slope. Hence the identification of directional amplifications should be taken into account in comprehensive seismic landslide hazard assessments. However, until now, the limited amount of observational data has not allowed a thorough understanding of factors controlling directional amplification and the definition of practical recognition criteria. Therefore, we carried out investigations to evaluate if seismic site response directivity can be revealed through quick and lowcost tests like the Nakamura's method (also called Horizontal to Vertical Noise Ratio - HVNR - technique), based on the calculation of the $\mathrm{H} / \mathrm{V}$ ratio (i.e. the ratio between horizontal and vertical component spectra) of recordings of ambient noise induced by natural and anthropic sources of microtremors (Nakamura, 1989).

The HVNR technique, despite its somewhat unclear theoretical bases (see Bonnefoy-Claudet et al., 2006a), has been diffusely applied in microzonation studies, mainly because peaks in the $\mathrm{H} / \mathrm{V}$ spectral ratios have proved to be an effective indicator of the resonance frequency of low-impedance surface layers. The technique remains popular even though the reliability of the associated estimate of the amplification factor is deemed questionable (Bonnefoy-Claudet et al., 2006b). At present the employment of this method can benefit from the recent introduction of a new portable instrument named "Tromino", with velocimeter characteristics, specifically designed for HVNR measurements.

Considering that Tromino allows 3-component recordings of microtremors also in difficult logistic conditions, we employed it to measure azimuthal variation of $\mathrm{H} / \mathrm{V}$ spectral ratios of microtremors on landslide-prone slopes at Caramanico Terme (central Italy). In this area, a long term monitoring has been undertaken since 2002 to study seismic response of slopes by means of a network of 5 accelerometric stations. The monitoring provided clear evidence of directivity in seismic response for two of these stations, one located on a landslide re-activated in 1989 and presently quiescent, and the other on the rim of a steep scarp in carbonate breccias overlying stratified limestones (Del Gaudio and Wasowski, 2007). This area represents a useful test site to experiment techniques for the identification of site response directivity, even though the exact causes of these phenomena are still being investigated. Indeed, the Caramanico area offers the possibility of comparing the results obtained from tests like
HVNR measurements carried out with portable instruments, with simultaneous recordings of permanent accelerographs and with the available database of seismic event recordings.

In particular, in this work the newly acquired results are compared with H/V spectral ratios obtained by Del Gaudio and Wasowski (2007) from seismic event recordings, integrated with additional more recent accelerometric data. Furthermore, we present HVNR measurements made in other locations on the 1989 landslide that confirm the influence of the landslide body on the directivity effects.

\section{Description of the study sites}

The study sites are on the peri-urban slopes of Caramanico Terme, a town located in Central Italy (Fig. 1). This area is located in a seismically active part of the Apennine chain, which in the past generated earthquakes of magnitude up to 7.0. Seismic shocks are recurrently felt at Caramanico and recent hazard estimates ("Gruppo di lavoro", 2004) indicate that a PGA value of $0.2 \mathrm{~g}$ has an exceedance probability of $10 \%$ in 50 years. Furthermore, several cases of slope failures induced by historical earthquakes have been documented and conditions for seismic slope failures have likely occurred also on other occasions (Wasowski and Del Gaudio, 2000).

The local geological setting, characterised by the presence of thick, often coarse colluvia of Quaternary age, overlying the relatively impermeable Pliocene mudstones, together with the persistance of high relief, make the Caramanico slopes highly susceptible to landsliding. Surficial deposits include loose to weakly cemented coarse limestone gravels and limestone blocks, as well as re-moulded clay-rich materials; the abrupt lateral and vertical changes of lithofacies (in part enhanced by the post-sedimentary disruption related to long history of mass movements) confer considerable complexity to the local slope settings (Wasowski and Del Gaudio, 2000).

Because of the recurrence of slope failures and frequent seismic activity the area of Caramanico has been selected as a test site for recent research projects on landslide phenomena and a local network of permanent accelerometric stations was set up to study slope response to seismic shaking in different lithostratigraphic and topographic conditions. The network includes 5 stations (see Fig. 1) equipped with accelerographs Kinemetrics model Etna:

1. CAR1, on a slope in Pliocene mudstones, locally dipping $18^{\circ}$ to WSW;

2. CAR2, $600 \mathrm{~m}$ to SSE of CAR1, within the same hillslope locally dipping $11^{\circ}$ to WSW, but on the head of a landslide that in 1989 mobilised a 30-40 m thick colluvium deposit overlying the same mudstones outcropping at CAR1; 

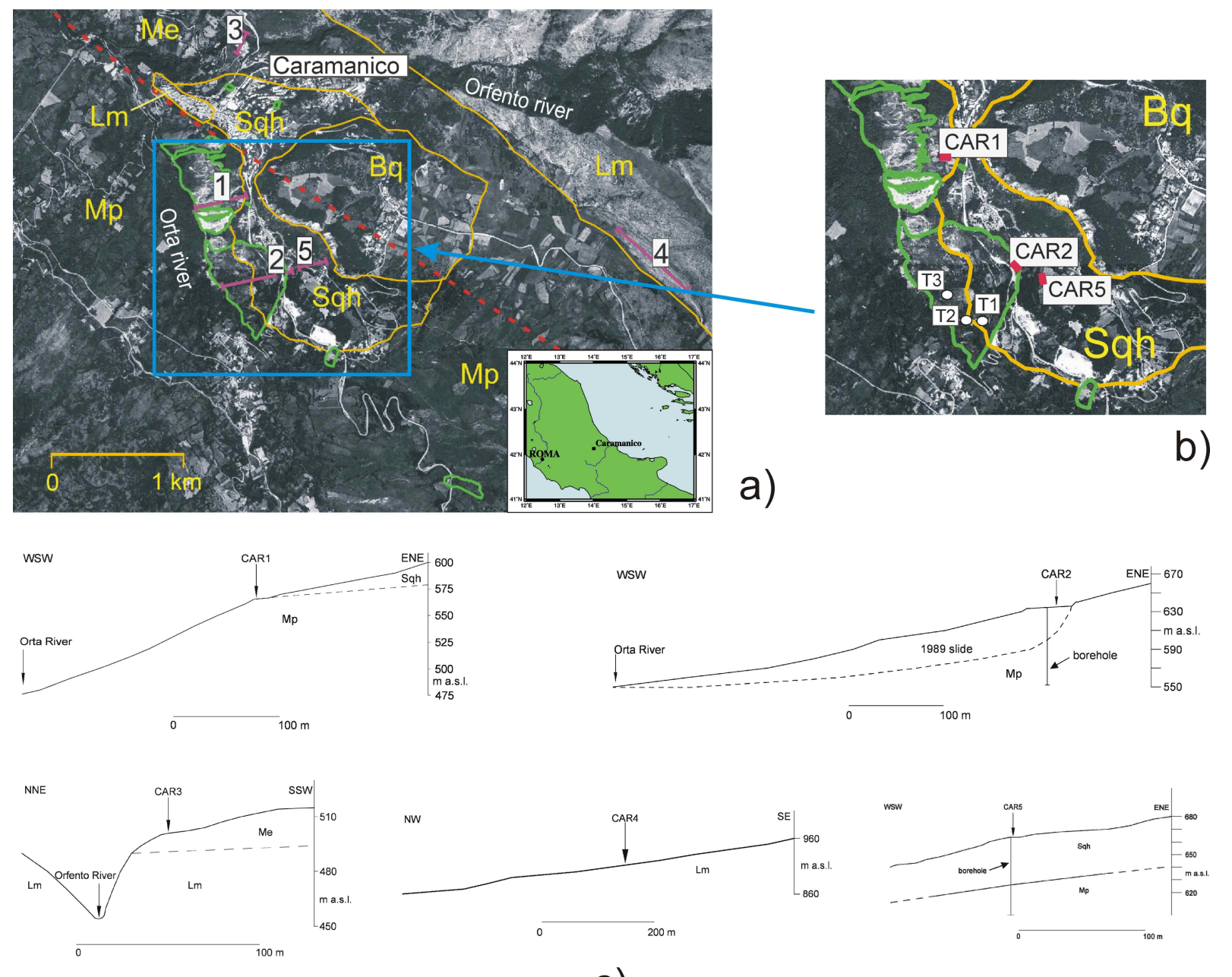

C)

Fig. 1. (a) Orthophoto of the study area showing lithological units and positions of measurement sites; geographical location marked on inset. Major landslides are indicated in green, geological contacts in brown and inferred fault in red (after Wasowski and Del Gaudio, 2000). Explanation: $\mathrm{Lm}=$ Miocene limestones; $\mathrm{Me}=$ Messinian sandy-silty deposits with carbonate breccia; $\mathrm{Mp}=\mathrm{Pliocene}$ mudstones; $\mathrm{Bq}=$ Quaternary limestone megabreccias; Sqh = Quaternary and Holocene soils (colluvium and artificial ground); numbers 1-5 mark the location of the accelerometric stations CAR1-CAR5. (b) Enlargement of the 1989 landslide area, showing the locations (T1, T2 and T3) of the HVNR measurements carried out on the slide body; (c) Geologic profiles of CAR1-5 sites constructed along the maximum slope directions (marked by purple lines in part (a). Note that horizontal and vertical scales are equal and that $\mathrm{m}$ a.s.l. stands for meters above sea level.

3. CAR3, on the rim of a gorge about $50 \mathrm{~m}$ deep, locally oriented WNW-ESE, on $10 \mathrm{~m}$ thick Messinian carbonate breccia deposit overlying Miocene limestones;

4. CAR4, $2.5 \mathrm{~km}$ SE of Caramanico, on the same limestones constituting the substratum at CAR3, which locally form a gentle slope dipping $8^{\circ}$ to NW;

5. CAR5, about $200 \mathrm{~m}$ east of CAR2 on the same colluvium as in CAR2, but upslope the 1989 landslide crown, in a gently inclined $\left(<7^{\circ}\right)$ area.

In five years these stations provided 98 recordings of 60 seismic events of magnitude up to 5.4 and distance from few to $160 \mathrm{~km}$. For two of these stations, CAR2 and CAR3, the analysis of directional variation of shaking energy, expressed in terms of Arias intensity (Arias, 1970), showed pronounced maxima systematically oriented along an almost constant direction in all the recorded events, regardless their source location.

This suggested the presence of a directional resonance in the dynamic response of these sites to seismic shaking. The directivity was further investigated by analyzing the directional variations of average horizontal to vertical spectral ratios (HVSR) calculated for the recorded seismic events. Theoretical considerations support the use of HVSR in site effect evaluations for the case of 1-D layering dynamic response (e.g. Lermo and Chávez-García, 1993), however this 


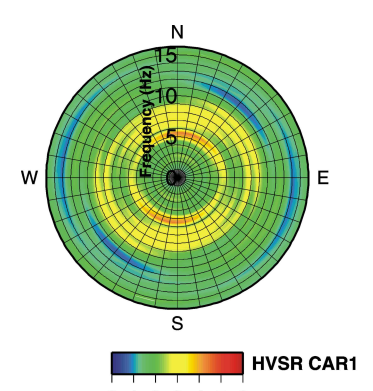

012234556
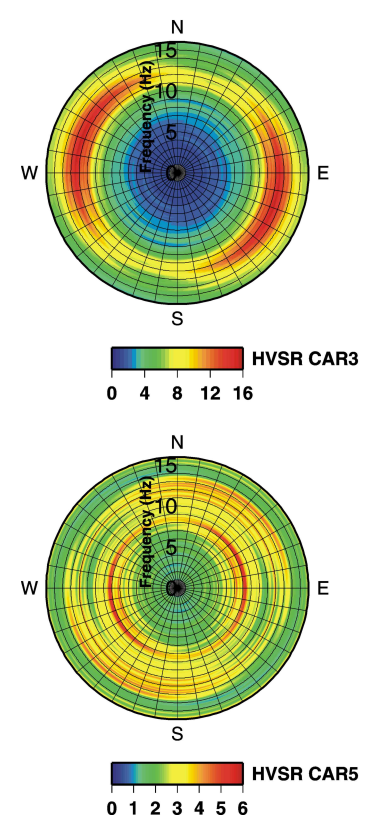

Fig. 2. Polar diagrams of mean HVSR (Horizontal-to-Vertical Spectral Ratios) values for stations CAR1, CAR2, CAR3, CAR4, CAR5 calculated at $10^{\circ}$ azimuth intervals for all the seismic events recorded at each station (see Fig. 1 for locations). Note that values of spectral ratios at CAR3 are much higher than at other stations and hence HVSR diagram scale is different.

technique has also been found suitable to identify resonance frequency in more complex situations, e.g. in presence of topographic amplification (Chávez-García et al., 1996). The results obtained at Caramanico revealed that, at the sites CAR2 and CAR3, HVSR values were characterised by directional spectral peaks at site-specific frequencies with orientations close to the mean direction of maximum shaking, i.e. $\mathrm{N} 100^{\circ} \mathrm{W}-\mathrm{N} 80^{\circ} \mathrm{E}$ and $\mathrm{N} 70^{\circ} \mathrm{W}-\mathrm{N} 110^{\circ} \mathrm{E}$, respectively (Del Gaudio and Wasowski, 2007).

Additional most recent recordings confirmed the earlier results from Caramanico. In Fig. 2 the mean HVSR values obtained from the total data set are represented by polar diagrams. Tables 1 and 2 list the absolute and main relative maxima of spectral ratios along with their relevant characteristics, i.e. frequency and azimuth of each maximum, the minimum spectral ratio found at the same frequency of maximum, the azimuth of the minimum and the quotient between HVSR maximum and minimum (MmQ). When the quotient
MmQ exceeds 1.5, the associated shaking energy in direction of maximum exceeds that in direction of minimum by more than a factor of 2. Thus MmQ=1.5 was assumed as a threshold to identify a significant directivity of site response at the corresponding frequency.

Both at CAR2 and CAR3, spectral ratios at several frequencies reach their maximum values at very close azimuths, dropping to a significantly lower value along perpendicular orientations (Table 1 ). At CAR2 the main peak (HVSR $\approx 6$ ) at $10.1 \mathrm{~Hz}$ and all the major secondary peaks $(\mathrm{HVSR} \geq 4)$ have $\mathrm{N} 80^{\circ}-90^{\circ} \mathrm{E}$ direction, which is very close to the direction of maximum slope and the mean direction of shaking energy maxima $\left(\mathrm{N} 100^{\circ} \mathrm{W}\right)$. At CAR3 the largest maxima (HVSR > 7) are distributed between 9 and $16 \mathrm{~Hz}$, with the main peak (HVSR $\approx 16$ at $12.4 \mathrm{~Hz}$ ) in $\mathrm{N} 80^{\circ} \mathrm{W}$ direction and secondary peaks with azimuths between $\mathrm{N} 80^{\circ} \mathrm{W}$ and $\mathrm{N} 60^{\circ} \mathrm{W}$. Thus the peaks are orientated approximately parallel to the gorge rim and diverge at most by $10^{\circ}$ from the mean direction of shaking energy maxima $\left(\mathrm{N} 70^{\circ} \mathrm{W}\right)$.

The other sites do not show a clear preferential direction in the azimuthal distribution of spectral energy (Table 2): at CAR1 major relative maxima are oriented along different directions distributed in an azimuth interval of about $80^{\circ}$; at CAR4 the HVSR values have no sharp peak (maximum spectral ratio is less than 3) and differences between maximum and minimum of spectral ratios at the same frequency are small; at CAR5 frequency bands showing maximum spectral ratios (at frequency $8-9 \mathrm{~Hz}$ and $11-12 \mathrm{~Hz}$ ) seem to have a nearly isotropic distribution of their values (Fig. 2). It is noteworthy that CAR1, CAR2 and CAR5 are all closely located on the same hillslope, characterised by the same Pliocene mudstone substratum, but only CAR2 is sited on the 1989 landslide body, whereas CAR5 is located just $200 \mathrm{~m}$ upslope the 1989 landslide, on colluvial deposits very similar to those affected by the landslide (Fig. 1). Thus the presence of site directivity at the site located on the landslide (CAR2) and its absence at the two sites located with a few hundred meters from the landslide suggest that the landslide body plays an important role in site response.

\section{Measurements}

In order to verify if the site response directivity and its properties can also be derived from HVNR measurements, reconnaissance investigations based on microtremor recordings were conducted at the 5 accelerometric sites of Caramanico. The measurements were done using the new portable seismograph Tromino. This instrument is a compact 3-component velocimeter (see http://www.tromino.it for instrument description) with a good instrumental response in a wide frequency interval. Thanks to its small size $(10 \times 14 \times 7.7 \mathrm{~cm})$ and weight $(1.1 \mathrm{~kg})$ Tromino is particularly suitable for measurements in rough terrain conditions like those of landslideprone slopes. 
Table 1. Main relative maxima of horizontal to spectral ratios in seismic (HVSR) and noise (HVNR) recordings at sites characterised by directivity in site response (CAR2 and CAR3): Freq = frequency; AzM = azimuth of maximum at the specified frequency; HVM = maximum spectral ratio at the same frequency; Azm = azimuth of minimum at the specified frequency; $\mathrm{HVm}=$ minimum spectral ratio at the same frequency; $\mathrm{MmQ}=$ Quotient $\mathrm{HVM} / \mathrm{HVm}$.

\begin{tabular}{|c|c|c|c|c|c|c|c|c|c|c|c|c|}
\hline & \multicolumn{6}{|c|}{$H V S R$} & \multicolumn{6}{|c|}{$H V N R$} \\
\hline & Freq & AzM & HVM & Azm & $\mathrm{HVm}$ & MmQ & Freq & AzM & HVM & Azm & $\mathrm{HVm}$ & $\mathrm{MmQ}$ \\
\hline \multirow{12}{*}{$C A R 2$} & & & & & & & 1.8 & 80 & 2.8 & -10 & 2.1 & 1.3 \\
\hline & 2.5 & 90 & 2.5 & 0 & 1.9 & 1.3 & 2.4 & 90 & 5.3 & 0 & 3.1 & 1.7 \\
\hline & 3.5 & 50 & 2.7 & -40 & 2.0 & 1.4 & 3.4 & 80 & 2.7 & -40 & 1.8 & 1.6 \\
\hline & & & & & & & 4.0 & 80 & 2.2 & -20 & 1.6 & 1.4 \\
\hline & 6.8 & 90 & 4.0 & 0 & 1.7 & 2.4 & 6.8 & 90 & 2.0 & 0 & 1.1 & 1.8 \\
\hline & 7.7 & 80 & 4.7 & -10 & 1.7 & 2.8 & 7.7 & 90 & 2.1 & 0 & 1.4 & 1.5 \\
\hline & 8.7 & 80 & 4.8 & -10 & 1.9 & 2.6 & 8.6 & 80 & 2.4 & -10 & 1.7 & 1.4 \\
\hline & 10.1 & 80 & 5.8 & -10 & 3.2 & 1.8 & 10.6 & 80 & 3.0 & 0 & 1.5 & 2.0 \\
\hline & 11.9 & 80 & 3.9 & 0 & 2.4 & 1.7 & & & & & & \\
\hline & 12.6 & 40 & 3.6 & -50 & 2.6 & 1.4 & & & & & & \\
\hline & 13.5 & 40 & 2.9 & -50 & 2.2 & 1.3 & 13.3 & 80 & 3.0 & -10 & 1.8 & 1.6 \\
\hline & & & & & & & 14.7 & 80 & 3.1 & -10 & 1.8 & 1.7 \\
\hline \multirow{13}{*}{ CAR3 } & 4.2 & 50 & 2.2 & -40 & 1.6 & 1.3 & 3.9 & -40 & 3.0 & 50 & 2.1 & 1.4 \\
\hline & 5.5 & 80 & 2.7 & -10 & 1.9 & 1.4 & 5.3 & -10 & 2.8 & 80 & 2.0 & 1.4 \\
\hline & 6.2 & 60 & 3.0 & -20 & 2.3 & 1.3 & 6.0 & -10 & 2.9 & 80 & 2.3 & 1.2 \\
\hline & 6.9 & 80 & 3.5 & 0 & 2.8 & 1.3 & 6.4 & 0 & 3.2 & -80 & 2.6 & 1.2 \\
\hline & 7.7 & 90 & 3.4 & 10 & 3.2 & 1.1 & 8.0 & -10 & 4.7 & 80 & 2.8 & 1.7 \\
\hline & 8.6 & -80 & 4.2 & 10 & 3.1 & 1.4 & & & & & & \\
\hline & 9.6 & -80 & 7.2 & 10 & 4.1 & 1.8 & 9.3 & -40 & 6.2 & 50 & 4.5 & 1.4 \\
\hline & 11.5 & -70 & 13.4 & 20 & 7.5 & 1.8 & & & & & & \\
\hline & 12.4 & -80 & 15.7 & 20 & 7.3 & 2.2 & 12.6 & -50 & 13.9 & 40 & 7.9 & 1.8 \\
\hline & 13.5 & -80 & 13.0 & 10 & 5.6 & 2.3 & & & & & & \\
\hline & 14.3 & -60 & 10.1 & 20 & 5.6 & 1.8 & & & & & & \\
\hline & 14.9 & -70 & 7.9 & 20 & 4.3 & 1.8 & & & & & & \\
\hline & 15.7 & -70 & 7.0 & 20 & 3.6 & 2.0 & & & & & & \\
\hline
\end{tabular}

Ambient noise was recorded at each accelerometric site for $15 \mathrm{~min}$ with a sampling rate of $128 \mathrm{sps}$ (sample per second). Tromino was positioned beside the accelerograph Etna and during the measurement session, for comparison purposes, noise recordings were also carried out with Etna, which operates at a sampling rate of $200 \mathrm{sps}$. The recordings obtained from Etna were corrected for the instrumental response using the procedure described by Shakal and Ragsdale (1984) with pass-band filtering in the interval $1-50 \mathrm{~Hz}$, and data were decimated to halve the sampling rate to $100 \mathrm{sps}$.

The noise recordings were subdivided into intervals of $30 \mathrm{~s}$, selecting the most stationary part of the recorded signals and excluding transient parts possibly associated to very close sources, according to the guidelines suggested by the project SESAME (Site EffectS assessment using AMbient Excitations: see http://sesame-fp5.obs.ujf-grenoble.fr/SES Reports.htm). Fourier spectra were calculated and smoothed using a triangular average on frequency intervals of $\pm 5 \%$ of the central frequency. The spectral ratios were then calculated between horizontal components oriented at $10^{\circ}$ azimuth intervals and vertical component and, finally, for each station, the average spectral ratios $\mathrm{H} / \mathrm{V}$ of all the recording intervals in each direction were obtained. As for the HVSR values, the "degree of directivity" of a spectral peak at a given frequency was evaluated through the parameter MmQ and a threshold of 1.5 was assumed to identify the presence of a significant directivity.

The evidence of directivity at the CAR2 site, located on the head of the 1989 landslide, prompted us to examine in more detail the role of the landslide in determining such phenomenon. For this reason additional noise measurements were carried out at three sites on the landslide (see Fig. 1 for location): two of them (T1 and T2) are in the middle part of the slide, mid-way between its central axis and the left-lateral boundary, where the landslide body is about $20 \mathrm{~m}$ thick and includes $10 \mathrm{~m}$ of carbonate breccia debris overlying reworked clays; the third site (T3) is near the center of the slide toe, where the landslide material (with estimated thickness of 10-15 m) consists mainly of reworked clays including isolated limestones blocks. 

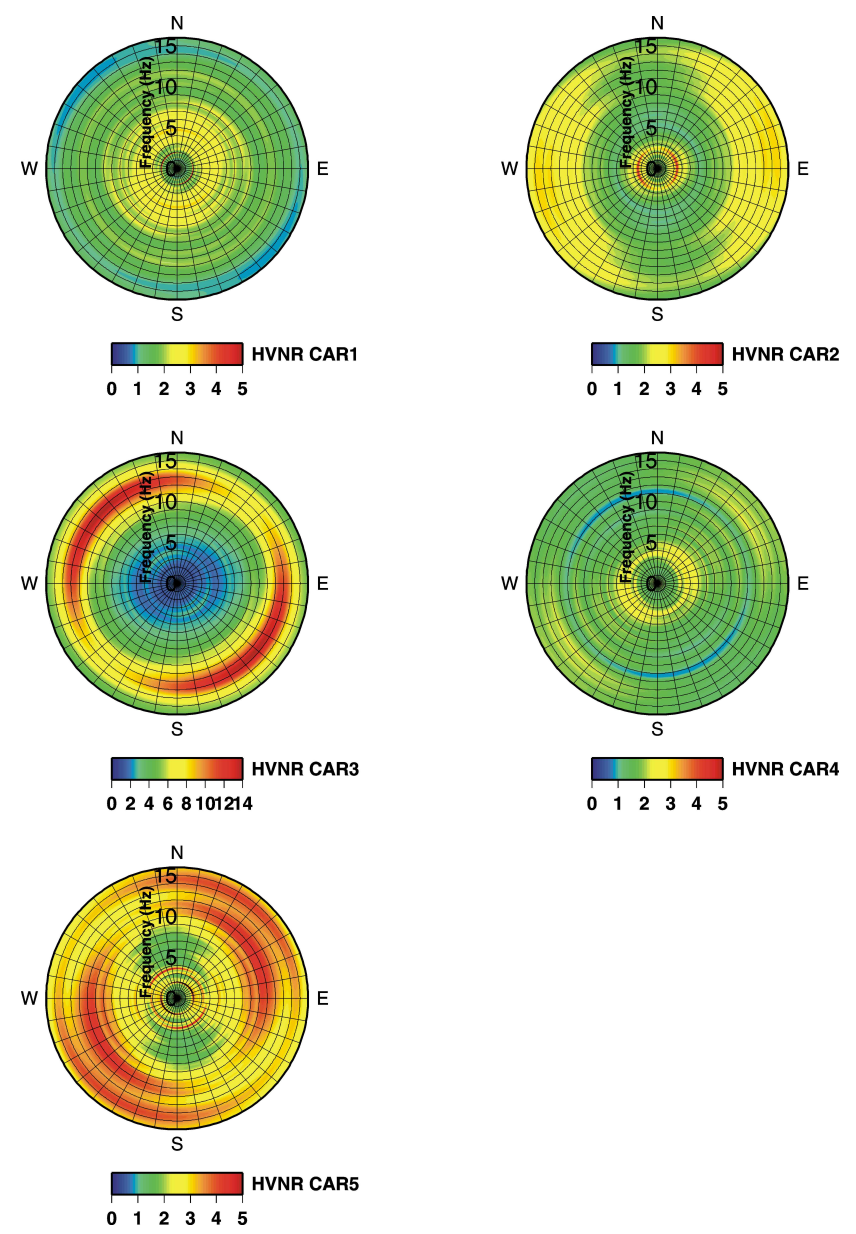

Fig. 3. Polar diagrams of mean HVNR (Horizontal-to-Vertical Noise Ratios) values at azimuth intervals of $10^{\circ}$ from microtremor recordings carried out with the portable seismograph Tromino, at the sites of the accelerometric stations CAR1, CAR2, CAR3, CAR4, CAR5. Note that values of spectral ratios at CAR3 are much higher than at other stations and hence HVSR diagram scale is different.

\section{Results and discussion}

\subsection{Comparison HVNR-HVSR}

Figure 3 shows polar diagrams of HVNR values obtained at the accelerometric sites by using Tromino seismograph. These can be compared with the HVSR diagrams derived from the seismic event recordings (Fig. 2). Tables 1-2 provide a comparison of the characteristics of relevant spectral ratio peaks for both seismic and noise recordings, showing side by side peaks having similar frequency (within $0.5 \mathrm{~Hz}$ ). In some cases no significant, distinct HVNR relative maximum was found to match a HVSR peak or, vice versa, some of HVNR maxima did not have a corresponding HVSR peak (blank fields in Tables 1-2): this can be due to the presence of low $\mathrm{H} / \mathrm{V}$ ratios or a fusion of two or more peaks that cannot be distinctly resolved.

With regard to the two sites showing directivity in seismic response (Table 1), a quite good agreement was found between the main peaks of HVNR and HVSR at CAR3 (Figs. 2 and 3). There HVNR is characterised by a maximum spectral ratio equal to 13.9 at frequency of $12.6 \mathrm{~Hz}$ in $\mathrm{N} 50^{\circ} \mathrm{W}$ direction, having a significant directivity $(\mathrm{MmQ}=1.8)$; it corresponds to the HVSR peak equal to 15.7 at frequency of $12.4 \mathrm{~Hz}$ in $\mathrm{N} 80^{\circ} \mathrm{W}$ direction for which $\mathrm{MmQ}$ is equal to 2.2 . More in general, both HVNR and HVSR diagrams show a similar strong concentration of spectral energy between 9 and $16 \mathrm{~Hz}$ with spectral ratios above 6 , despite a general divergence of $30-40^{\circ}$ between the directions of HVNR and HVSR maxima. It should be stressed, however, that, for each kind of recording (seismic or noise), major spectral ratio peaks do not diverge by more than $20^{\circ}$ from each other and by no more than $30^{\circ}$ from the mean direction of the shaking energy maxima observed during the earthquakes. These divergences could be due to the influence of possible different polarizations in signal sources.

As far as CAR2 is concerned, amplitude and degree of directivity of spectral ratios obtained from seismic and noise recording for similar frequencies are quite different. Therefore directional maxima of HVNR and HVSR are found at different frequencies (Figs. 2 and 3) and major peaks in one diagram (e.g. at $2.4 \mathrm{~Hz}$ for HVNR and at $10.1 \mathrm{~Hz}$ for HVSR) correspond to rather modest relative maxima of the other (e.g. the $2.5 \mathrm{~Hz}$ peak of HVSR and the $10.6 \mathrm{~Hz}$ peak of HVNR, which are approximately $1 / 2$ of those mentioned above). However, despite these differences, all the relative HVNR and HVSR maxima share a very similar orientation, great majority of them falling within the $\mathrm{N} 80^{\circ}-90^{\circ} \mathrm{E}$ azimuth range, i.e. very close to the mean direction of shaking energy maxima $\left(\mathrm{N} 80^{\circ} \mathrm{E}\right)$.

The H/V spectral ratios obtained at the other sites (Table 2) do not seem to show a clear systematic directivity of major HVNR and HVSR peaks. At CAR1, for instance, the main HVSR peak at $5.5 \mathrm{~Hz}$ has a similarly oriented counterpart among HVNR secondary peaks at $5.8 \mathrm{~Hz}$, even though with a weaker directivity. Instead, the main HVNR peak at $1.9 \mathrm{~Hz}$, which has a strong directivity $(\mathrm{MmQ}=4.1)$, diverges $60^{\circ}-70^{\circ}$ from the direction of major secondary peaks and also $50^{\circ}$ from the direction of HVSR relative maximum of similar frequency at $2.1 \mathrm{~Hz}$. It is noteworthy that some of the major HVSR peaks (e.g. that at $7.4 \mathrm{~Hz}$ ) do not have a marked directional character and the directivity of others do not appear to be a site property. A previous analysis conducted on separate groups of seismic event recordings indicated that such directivity probably reflects wave polarization related to common source characteristics of several events belonging to a single seismic sequence (Del Gaudio and Wasowski, 2007). The strong directivity of the $1.9 \mathrm{~Hz}$ peak, which is the only HVNR peak with a significant directional character could likewise reflect polarization properties of a single noise 
Table 2. Main relative maxima of horizontal to spectral ratios in seismic (HVSR) and noise (HVNR) recordings at sites CAR1, CAR4 and CAR5: Freq = frequency; AzM = azimuth of maximum at the specified frequency; HVM = maximum spectral ratio at the same frequency; $\mathrm{Azm}=$ azimuth of minimum at the specified frequency; $\mathrm{HVm}=$ minimum spectral ratio at the same frequency; $\mathrm{MmQ}=\mathrm{Quotient} \mathrm{HVM} / \mathrm{HVm}$.

\begin{tabular}{|c|c|c|c|c|c|c|c|c|c|c|c|c|}
\hline & \multicolumn{6}{|c|}{ HVSR } & \multicolumn{6}{|c|}{ HVNR } \\
\hline & Freq & AzM & HVM & Azm & $\mathrm{HVm}$ & MmQ & Freq & AzM & HVM & Azm & $\mathrm{HVm}$ & $\mathrm{MmQ}$ \\
\hline \multirow{8}{*}{$C A R 1$} & 2.1 & -10 & 2.3 & 90 & 2.0 & 1.1 & 1.9 & -60 & 5.6 & 30 & 1.4 & 4.1 \\
\hline & & & & & & & 3.9 & 10 & 3.0 & -50 & 2.8 & 1.1 \\
\hline & & & & & & & 4.7 & 0 & 3.2 & 90 & 2.5 & 1.2 \\
\hline & 5.5 & 10 & 4.6 & -80 & 2.8 & 1.7 & 5.8 & 20 & 2.7 & -60 & 2.1 & 1.3 \\
\hline & 6.6 & -20 & 3.2 & 70 & 1.9 & 1.6 & 7.0 & 0 & 2.5 & -80 & 2.2 & 1.2 \\
\hline & 7.4 & -20 & 3.2 & 80 & 2.2 & 1.5 & & & & & & \\
\hline & 8.0 & 0 & 2.9 & 80 & 2.2 & 1.3 & 8.1 & 50 & 2.2 & -40 & 1.8 & 1.2 \\
\hline & 9.8 & 60 & 3.2 & -30 & 1.7 & 1.9 & & & & & & \\
\hline \multirow{8}{*}{ CAR4 } & 2.4 & 50 & 1.5 & -40 & 1.1 & 1.4 & 2.9 & 70 & 2.4 & -30 & 1.7 & 1.4 \\
\hline & & & & & & & 3.6 & 70 & 2.7 & -20 & 2.2 & 1.2 \\
\hline & & & & & & & 4.5 & 60 & 2.6 & -30 & 2.0 & 1.3 \\
\hline & & & & & & & 5.2 & 70 & 2.2 & -20 & 1.8 & 1.2 \\
\hline & 5.8 & 70 & 1.6 & -20 & 1.1 & 1.5 & 6.0 & 70 & 2.3 & -20 & 1.4 & 1.7 \\
\hline & 8.4 & 50 & 2.5 & -40 & 1.5 & 1.7 & 8.0 & 60 & 2.0 & -30 & 1.4 & 1.5 \\
\hline & 9.4 & 60 & 2.5 & -40 & 1.7 & 1.5 & & & & & & \\
\hline & 10.3 & 50 & 2.9 & -40 & 1.7 & 1.7 & 10.2 & 60 & 2.1 & -30 & 1.4 & 1.5 \\
\hline \multirow{20}{*}{ CAR5 } & 1.9 & 80 & 2.3 & -20 & 1.7 & 1.4 & 1.9 & 50 & 6.2 & -50 & 2.4 & 2.6 \\
\hline & 3.4 & -80 & 2.5 & 10 & 1.6 & 1.6 & 3.6 & -20 & 4.3 & 70 & 1.6 & 2.7 \\
\hline & & & & & & & 3.9 & 70 & 2.3 & -10 & 2.0 & 1.2 \\
\hline & & & & & & & 4.8 & 90 & 2.6 & 0 & 1.4 & 1.9 \\
\hline & 5.7 & 80 & 3.1 & -20 & 2.0 & 1.5 & 5.4 & 80 & 3.2 & -10 & 1.3 & 2.5 \\
\hline & 6.1 & 70 & 3.7 & -20 & 1.5 & 2.5 & & & & & & \\
\hline & 7.0 & 90 & 4.0 & -10 & 1.3 & 3.0 & & & & & & \\
\hline & 7.6 & 60 & 4.1 & -30 & 2.1 & 1.9 & & & & & & \\
\hline & 8.2 & 70 & 6.3 & 0 & 4.4 & 1.4 & & & & & & \\
\hline & 8.4 & -40 & 6.2 & 60 & 5.5 & 1.1 & & & & & & \\
\hline & 8.9 & 30 & 3.8 & -60 & 2.2 & 1.7 & 9.2 & 80 & 3.8 & -10 & 2.5 & 1.5 \\
\hline & 9.5 & 10 & 3.5 & 90 & 2.2 & 1.6 & & & & & & \\
\hline & 10.3 & 20 & 3.8 & -70 & 2.1 & 1.8 & & & & & & \\
\hline & 10.8 & 10 & 3.2 & -80 & 1.7 & 1.9 & 10.9 & 60 & 4.2 & -60 & 2.8 & 1.5 \\
\hline & 11.2 & 30 & 4.6 & -70 & 2.3 & 2.0 & & & & & & \\
\hline & 11.9 & 70 & 5.7 & -30 & 4.6 & 1.2 & & & & & & \\
\hline & 12.5 & -20 & 3.7 & 60 & 2.2 & 1.7 & & & & & & \\
\hline & 13.3 & 50 & 4.0 & -50 & 1.9 & 2.1 & 12.9 & 50 & 3.4 & -40 & 2.5 & 1.4 \\
\hline & 15.3 & 40 & 2.5 & -40 & 1.6 & 1.5 & 15.2 & 30 & 3.6 & -60 & 2.8 & 1.3 \\
\hline & 15.9 & -80 & 3.5 & 20 & 2.8 & 1.2 & & & & & & \\
\hline
\end{tabular}

source rather than site response properties, because it has a direction different from that of any other HVNR or HVSR peaks.

At CAR4 the spectral ratios are lower than at the other CAR sites (H/V values below 3.0). Some correspondence in frequency and orientation can be found between HVNR and HVSR peaks, however the major HVNR peaks do not have directional character and do not match any significant HVSR relative maxima. The only HVNR peak with an appreciable directivity, at $6.0 \mathrm{~Hz}$, matches a minor HVSR peak at $5.8 \mathrm{~Hz}$, whereas major HVSR peaks with a significant direc- tivity (e.g. those at frequencies 8.4 and $10.3 \mathrm{~Hz}$ ) match rather secondary HVNR relative maxima. On the whole, spectral ratios of seismic events and noise recordings do not provide indications of important resonance phenomena for this site; indeed CAR4 had been located on a rock outcrop to act as a local reference station.

The HVNR values for CAR5 exibit several peaks at different frequencies. Some of the major peaks with spectral ratios higher than 3 show a significant directivity (MmQ up to 2.7 ), but are marked by a variable azimuthal distribution (from $\mathrm{N} 20^{\circ} \mathrm{W}$ to $\mathrm{N} 80^{\circ} \mathrm{E}$; Fig. 3). They have counterparts 

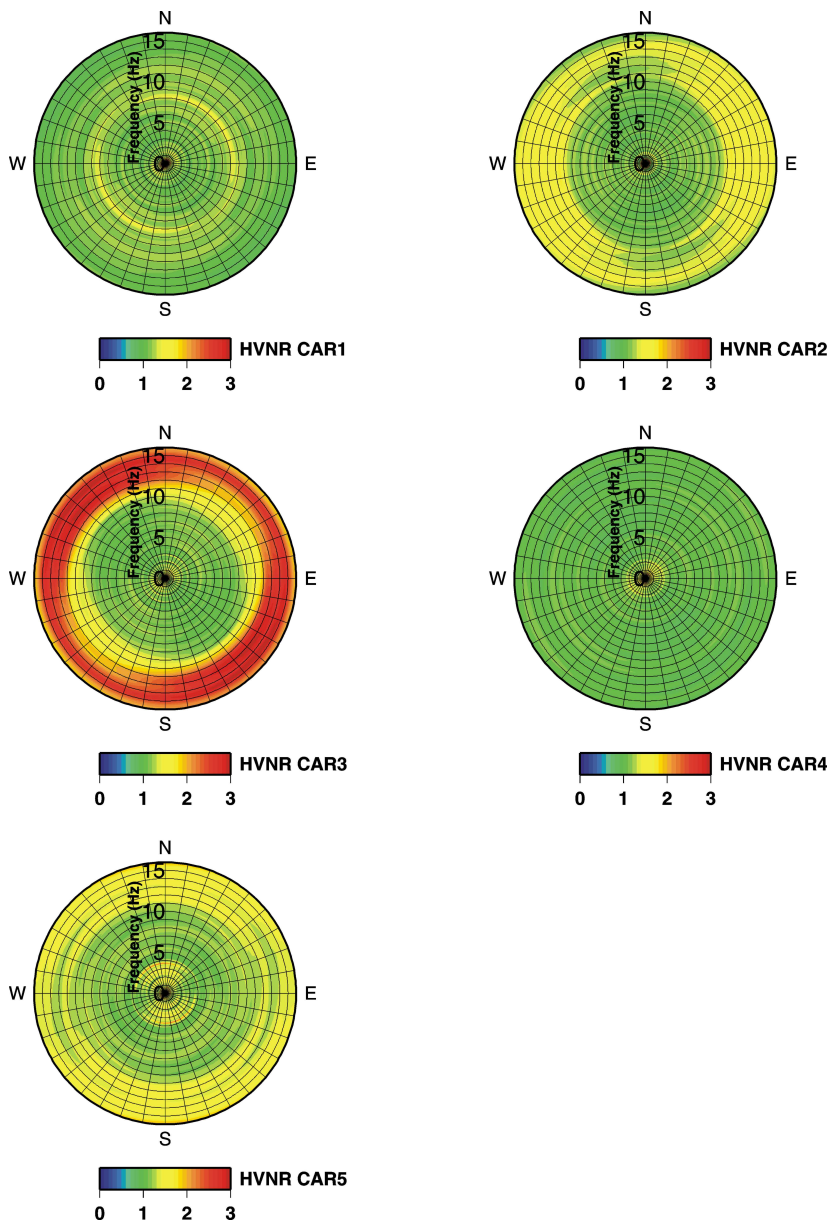

Fig. 4. Polar diagrams of mean HVNR values at azimuth intervals of $10^{\circ}$, obtained from microtremor recordings with accelerograph Kinemetrics Etna carried out simultaneously with Tromino measurements at the sites CAR1, CAR2, CAR3, CAR4, CAR5.

with similar frequency among HVSR peaks, but these appear as secondary maxima and their azimuths differ from those of the corresponding HVNR peaks by up to $60^{\circ}$. On the other hand, the numerous HVSR peaks with spectral ratio larger than 3 are oriented in very variable directions, but only few of them match a relative maximum in HVNR values.

On the whole, at the stations affected by a clear directivity in site response (CAR2 and CAR3), both within seismic event signals and noise recordings the directions of significant maxima of horizontal to vertical spectral ratio are consistent at different frequencies (Tables 1 and 2). Nevertheless, the comparisons reveal that spectral ratios and "degree of directivity" can be quite different for HVSR and HVNR peaks at similar frequencies. These differences could be in part due to the specific characteristics of the instruments employed (Etna and Tromino) for the two types of measurements.

\subsection{Influence of instrumental properties on HVNR-HVSR differences}

The influence of the instrumental properties on the differences found between the measurements of HVNR (made with Tromino) and HVSR (from Etna recordings) were investigated by a comparative analysis of their simultaneous noise recordings. The polar diagrams of HVNR obtained from Etna noise recordings (Fig. 4) show that the spectral ratios do not exceed 3, with most of them being below 2 . These values are significantly lower than HVNR obtained from Tromino recordings (Fig. 3). This made very difficult the recognition of spectral peaks, even though a more detailed analysis showed that some weak relative maxima in Etna noise recording spectra matched peaks pointed out also by Tromino data (Tables 1 and 2). Among the Etna data, spectral ratios higher than 2 were found only at CAR3 (i.e. the most amplified site), for the two major peaks at 13.1 and $14.7 \mathrm{~Hz}$, in the same direction and at similar frequencies as those of some of the highest Tromino HVNR peaks; the spectral ratios of the latter, however, were 4-5 times larger.

To investigate the reasons of this large discrepancy, simultaneous noise recordings acquired by the two instruments were compared by dividing the spectrum of each Etna recording component by the corresponding Tromino recording spectrum. In Fig. 5 the mean values of the obtained ratios are presented graphically as function of frequency. The graphs show similar trends with an initial steep decrease, which reflects Tromino instrumental response at low frequencies, followed by a gentle increase. In general the Etna/Tromino spectrum ratios relative to the two horizontal components appear consistent, whereas the ratios between the vertical components often show major divergences and are almost always higher. A maximum discrepancy is observed at station CAR3 (Fig. 5), where the spectral ratios of the vertical component at about $13 \mathrm{~Hz}$ exceed those of the horizontal components approximately by a factor of $4-5$; this explains the reduction by a similar factor of the HVNR derived from Etna in comparison to those obtained with Tromino.

Since in each instrument the sensors measuring different components are identical, the ratios of homologous component spectra should simply reflect differences in instrumental responses common to all the components. Therefore the observed discrepancies, varying through the spectrum and from one site to another, are likely due to a different content of instrumental noise, especially that affecting the vertical component. In particular, the higher level of noise on the Etna vertical component reduces significantly the $\mathrm{H} / \mathrm{V}$ ratio values at the low level of signal that characterises the microtremor recordings. However, noise could bias also $\mathrm{H} / \mathrm{V}$ ratios measurements for seismic events at frequencies where signal level is low, i.e. at frequencies different from those receiving a significant amount of shaking energy (which depend on source magnitude and distance and on local resonance 

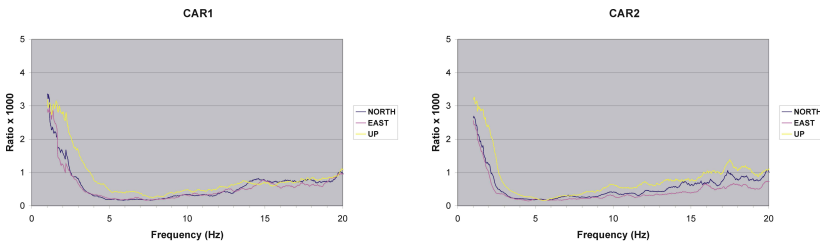

CAR3
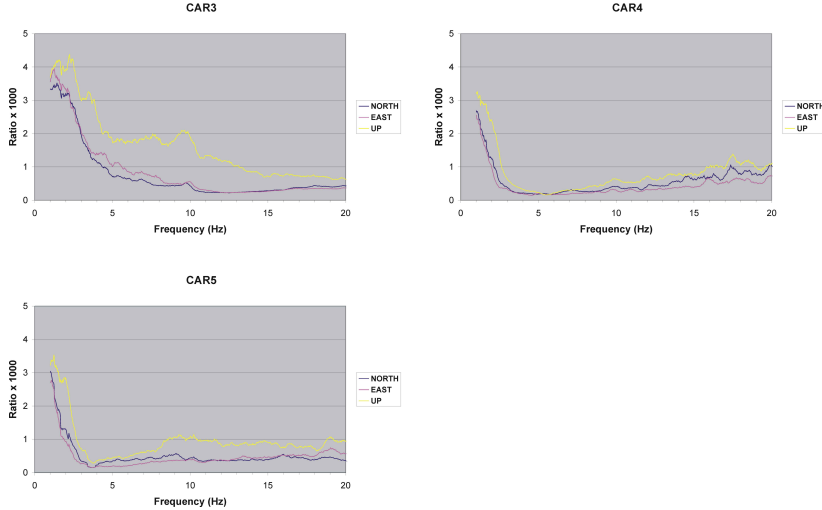

Fig. 5. Mean values of ratios between spectra of simultaneous noise recordings carried out with Etna and Tromino at the sites CAR1, CAR2, CAR3, CAR4, CAR5, calculated for each component (North, East, vertical).

frequencies of the recording site).

A similar problem might also affect Tromino HVNR measurements at frequencies for which signal/noise ratio is low for this instrument. Therefore, differences in the signal/noise ratio throughout the spectrum can be responsible of discrepancies between HVSR values derived from Etna and HVNR derived from Tromino, according to the spectral characteristics of signals (generated by earthquakes or by microtremor sources) and of resonance characteristics of sites. This can explain why major peaks of HVNR and HVSR values are mostly found at different frequencies.

More in general, our observations confirm what is already known about the inadequacy of accelerometers for noise measurements: these should be carried out with more sensitive high-gain seismometers, as proposed in Mucciarelli (1998) and confirmed by the SESAME project (Guillier et al., 2007).

\subsection{Provisional criteria for site response directivity identi- fication from HVNR}

It is opportune to stress that the combination of topographic and geologic factors controlling local seismic response at Caramanico is more complex than a simple 1-D layering structure for which the HVNR method was originally intended. The results of the HVNR-HVSR analysis reported above indicate that, in such settings, the horizontal to vertical spectral ratios derived from microtremor and earthquake recordings may not be directly comparable and may provide quite different outcomes in terms of peak frequencies. This derives from both the complexity of the site spec-
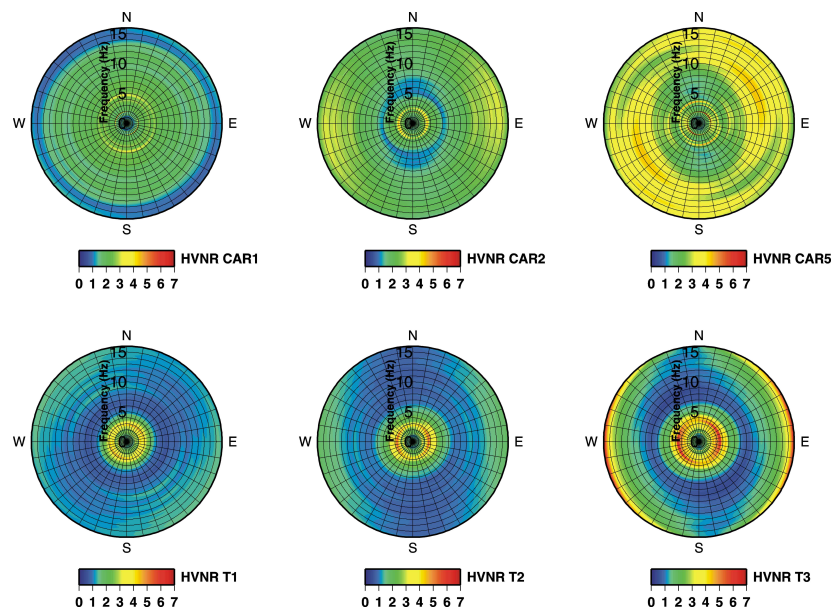

Fig. 6. Polar diagrams of mean HVNR values at azimuth intervals of $10^{\circ}$ obtained from microtremor recordings carried out with the portable seismograph Tromino on the 1989 landslide (sites CAR2, $\mathrm{T} 1, \mathrm{~T} 2, \mathrm{~T} 3$ ) and 600 and $200 \mathrm{~m}$ away from the slide (sites CAR1 and CAR5).

tral response, including several resonance frequencies, and from differences in instrument capacities to provide good signal/noise ratio in different frequency bands. Furthermore, in such situations the resulting $\mathrm{H} / \mathrm{V}$ spectral ratios cannot be considered as representative of the actual spectral amplification function, because of the possible presence of amplification-deamplification of the ground motion vertical component (cf. Del Gaudio and Wasowski, 2007).

Nevertheless noise recordings appear usable for the recognition of site response directivity. In particular, the results of our tests suggest that for a reliable identification of directivity in the site response the following three main conditions need to be met:

1. Peaks with significant $H / V$ spectral ratio values (not less than 2) having a significant directivity (maximum/minimum quotient larger than 1.5) should be identified in the azimuthal distribution of HVNR values;

2. If only one peak with a significant directivity is found, repeated measurements have to be performed at different hours and week days, to rule out the possibility that the single directional maximum is due to a source of polarised noise and thus may not reflect site properties;

3. Major directional peaks should have similar directions (within an azimuth interval of $20^{\circ}-30^{\circ}$ ); otherwise differently oriented pronounced peaks could reflect the coexistence of different sources of polarised noise at different azimuths. 
Clearly, considering the limited number of cases examined, at this stage these criteria are to be considered as provisional and will require further tests to be confirmed. However it is encouraging to observe that, among the five sites analysed, both and only the two ones for which a systematic directivity was observed in seismic shaking energy show multiple major peaks in $\mathrm{H} / \mathrm{V}$ spectral ratios that share a pronounced directivity consistent with maximum shaking direction. The fact that this feature was observed for signal of different nature and origin like seismic event and ambient noise, make us confident that it reflects site-specific directivity properties, which apparently can be revealed even under conditions where $\mathrm{H} / \mathrm{V}$ spectral ratios are not a reliable indicator of amplification factors and resonance frequencies.

\subsection{Results of HVNR measurement on landslide}

One of the significant findings regarding site response directivity at Caramanico was the detection of such phenomenon at the site CAR2 located on the 1989 landslide (Fig. 1, Del Gaudio and Wasowski, 2007). The comparison between the spectra obtained at CAR2 and at CAR1, the latter sited on an outcrop of the landslide substratum, led Del Gaudio and Wasowski (2007) to hypothesise that the landslide body is one of the factors causing the observed directivity (even though probably not the only one).

To test this hypothesis we conducted noise measurements at three sites located on the same landslide body (T1, T2, T3 - see Fig. 1 for location). Figure 6 shows the azimuthal variations of HVNR for the three sites and Table 3 summarises the main relative maxima. A comparison of these diagrams with each other and also with the HVNR results relative to CAR2 (Table 1), reveals several characteristics in common, e.g. the presence of high spectral ratios at frequencies less than $5-6 \mathrm{~Hz}$, with major peaks between 2 and $4 \mathrm{~Hz}$ oriented along similar directions. In particular, all three sites show at frequencies $2.3-2.5 \mathrm{~Hz}$ a significant $\mathrm{H} / \mathrm{V}$ ratio maximum of 4.4-5.0 in $\mathrm{N} 80^{\circ} \mathrm{E}$ direction, which matches quite well the characteristics of the main CAR2 HVNR peak (frequency $=2.4 \mathrm{~Hz}$, azimuth $=\mathrm{E}-\mathrm{W}$, spectral ratio=5.3). A similar peak is not present at sites CAR1 and CAR5 located on the same slope, but distant, respectively, $600 \mathrm{~m}$ and $200 \mathrm{~m}$ from the slide. Furthermore, apart from T1, all the other sites on the landslide show several additional peaks with a similar orientation (Table 3). At T3 this is the case of the two major peaks at $3.6 \mathrm{~Hz}$ and $16.0 \mathrm{~Hz}$, with orientations $\mathrm{N} 80^{\circ} \mathrm{E}$ and E-W, respectively, and also of other significant peaks with a pronounced directivity (e.g. at 1.9 and $15.2 \mathrm{~Hz}$ ). At T2 the main peak at $2.8 \mathrm{~Hz}$ and most of the secondary maxima have directions between $\mathrm{E}-\mathrm{W}$ and $\mathrm{N} 70^{\circ} \mathrm{E}$; these maxima sometimes exibit a significant directivity (MmQ up to 2.0).

A different situation is encountered at the $\mathrm{T} 1$ site, where the main peak at $2.8 \mathrm{~Hz}$ has a $\mathrm{N} 50^{\circ} \mathrm{E}$ direction and other secondary peaks show a variable azimuthal distribution. Furthermore, apart from the $2.3 \mathrm{~Hz}$ peak, common to all the sites on the landslide, none of the other peaks has a marked directional character $(\mathrm{MmQ}<1.5)$.

On the whole, the HVNR data indicate a different degree of site response directivity for the three sites located on the landslide. No convincing evidence of directivity was found at $\mathrm{T} 1$, while its presence appears clear at $\mathrm{T} 3$, where almost all the peaks having maximum spectral ratios greater than 2 are distributed within an azimuth interval of $30^{\circ}$ (from N $70^{\circ} \mathrm{E}$ to $\mathrm{N} 100^{\circ} \mathrm{E}$ ). Furthermore, most of these peaks have a pronounced directivity (MmQ from 1.5 to 5.8). This is in good agreement with what was observed at CAR2 also sited on the slide. The site $\mathrm{T} 2$ has several peaks showing maxima consistently orientated in the same azimuth interval as at T3. However, the evidence of directivity is less strong at T2, because only the $2.4 \mathrm{~Hz}$ peak is characterised both by a high spectral ratio (4.5) and a significant directivity $(\mathrm{MmQ}=1.6)$; other peaks have either high spectral ratios with low directivity (e.g. at $3.1 \mathrm{~Hz}$, with spectral ratio 4.1 , but $\mathrm{MmQ}=1.3$ ), or low spectral ratios and high directivity (e.g. the peaks at frequencies higher than $12 \mathrm{~Hz}$, with spectral ratios between 1.6 and 2.0 and $\mathrm{MmQ}=1.8 \div 2.0$ ).

In summary, these observations support the notion that the presence of a landslide body can provide a significant contribution to determine conditions of site response directivity. This, however, does not necessarily imply the persistence of directivity throughout the landslide extension, in that the concomitance of more factors (e.g. significant lateral variations in thickness and in material properties of the landslide body, local topography) can probably locally enhance or reduce such phenomenon.

\section{Conclusions}

The results of comparisons of horizontal to vertical spectral ratios derived from the recordings of seismic events and microtremors in Caramanico indicate that this kind of measurements can be useful for the recognition of site response directivity phenomena. The data acquired in situ confirm that these phenomena, affecting particularly slope areas, have rather complex origins. Directivity seems to be influenced by concomitant topographic and geological factors contributing to polarise a large amount of shaking energy along relatively narrow azimuth intervals centred on main directions related to local topography features. A consequence of this complexity is that sites affected by directional amplification are characterised by multiple resonance frequencies and that, therefore, several directional spectral peaks can be found at different frequencies along similar directions.

In such settings the calculation of horizontal to vertical spectral ratios derived from seismic events (HVSR) or microtremor measurements (HVNR) can provide quite variable peak frequencies in relation to the signal-to-noise ratio characterizing recordings in different frequency bands (in this context "signal" means the part of recording generated 
Table 3. Main relative maxima of HVNR at three sites on 1989 landslide: Freq = frequency; AzM = azimuth of maximum at the specified frequency; $\mathrm{HVM}=$ maximum spectral ratio at the same frequency; $\mathrm{MmQ}=$ Quotient between maximum and minimum spectral ratio.

\begin{tabular}{|c|c|c|c|c|c|c|c|c|c|c|c|}
\hline \multicolumn{4}{|c|}{$T 1$} & \multicolumn{4}{|c|}{$T 2$} & \multicolumn{4}{|c|}{$T 3$} \\
\hline Freq & AzM & HVM & $\mathrm{MmQ}$ & Freq & AzM & HVM & $\mathrm{MmQ}$ & Freq & AzM & HVM & $\mathrm{MmQ}$ \\
\hline 1.1 & -30 & 1.6 & 1.1 & & & & & & & & \\
\hline \multirow[t]{2}{*}{1.7} & 80 & 3.0 & 1.3 & 1.6 & -80 & 2.8 & 1.2 & 1.6 & 40 & 4.4 & 1.2 \\
\hline & & & & & & & & 1.9 & 80 & 3.8 & 1.7 \\
\hline 2.3 & 80 & 4.4 & 1.6 & 2.4 & 80 & 4.8 & 1.6 & 2.5 & 80 & 5.0 & 1.3 \\
\hline 2.8 & 50 & 4.8 & 1.3 & 2.8 & 70 & 5.4 & 1.5 & 2.8 & 90 & 6.1 & 1.4 \\
\hline 3.2 & 20 & 4.1 & 1.4 & 3.1 & 80 & 4.1 & 1.3 & 3.6 & 80 & 7.3 & 1.5 \\
\hline \multirow[t]{4}{*}{4.1} & 40 & 2.3 & 1.3 & 4.2 & 0 & 2.6 & 1.1 & 4.0 & 40 & 5.2 & 1.2 \\
\hline & & & & 4.9 & 50 & 2.1 & 1.3 & 4.5 & -80 & 4.9 & 1.6 \\
\hline & & & & 5.4 & 70 & 1.6 & 1.4 & & & & \\
\hline & & & & 6.0 & 60 & 1.6 & 1.2 & 5.9 & 80 & 2.5 & 1.7 \\
\hline \multirow[t]{3}{*}{9.2} & 0 & 1.3 & 1.2 & & & & & & & & \\
\hline & & & & 9.8 & 80 & 1.3 & 1.4 & & & & \\
\hline & & & & 12.9 & 80 & 1.6 & 1.8 & 13.2 & 70 & 2.6 & 2.2 \\
\hline \multirow[t]{2}{*}{13.9} & -50 & 1.5 & 1.3 & 13.7 & 80 & 1.6 & 1.8 & & & & \\
\hline & & & & 14.3 & 90 & 1.6 & 1.9 & & & & \\
\hline \multirow[t]{3}{*}{15.2} & -60 & 1.7 & 1.3 & & & & & 15.2 & 80 & 4.2 & 3.4 \\
\hline & & & & 15.8 & 90 & 1.9 & 2.0 & & & & \\
\hline & & & & 16.0 & 90 & 2.0 & 1.9 & 16.0 & 90 & 7.3 & 5.8 \\
\hline
\end{tabular}

by ground motion and "noise" refers to the part generated inside the acquisition system). Therefore, under the conditions of site response complexity typical of slopes with both topographic and lithostratigraphic amplification, HVNR and HVSR measurements alone cannot provide a complete and reliable identification of resonance frequencies and amplification factors. Nevertheless the results of our tests prove that techniques based on the analysis of horizontalto-vertical spectral ratios can be usefully employed in investigations of directivity properties of site response. Indeed, among the 5 sites investigated, both and only the two sites affected by such directivity phenomena showed multiple significant maxima of $\mathrm{H} / \mathrm{V}$ spectral ratios with orientations similar (within 20-30 ) to the mean directions of shaking energy maxima observed during low-to moderate earthquakes. In particular, this offers the possibility of using quick and cheap ambient noise recordings, carried out with portable seismograph, as reconnaissance technique to be implemented in wide-area investigations of slopes potentially prone to dangerous consequences of directional amplifications (e.g. earthquake-induced landslides). To identify directivity, one should verify the presence of more peaks with significantly high HVNR ratios and with pronounced and consistently oriented directivity; the existence of a single directional peak or differently oriented relative maxima is not diagnostic enough, because it could simply reflect the presence of one or more sources of polarised noise.

Finally, the results of the new analyses offered in this work confirmed the earlier hypothesis (Del Gaudio and Wasowski, 2007) that the presence of a pre-existing deep-seated landslide body can be a relevant factor in causing directivity in site response of slope areas. However, it is likely that local topographic conditions and significant variations in slide thickness and in material properties can considerably enhance or decrease the importance of this effect. Clearly further research on slopes susceptible to seismic failures is needed to provide some practical guidelines in reference to settings where the presence of a landslide should be considered as a potential cause of site response directivity.

Acknowledgements. We are grateful to Silvia Castellaro (Dipartimento di Fisica - Università di Bologna) for her support and useful discussions on Tromino data processing. This work was carried out with the financial support of the Italian Ministry of University and Research through the Project of National Interest (PRIN05) entitled "Induced seismic hazard: analysis, modelling and predictive scenarios of earthquake triggered landslides". The installation of the local accelerometric network at Caramanico was supported by the project LEWIS, funded by the European Commission within the 5th Framework Program, and by the Project S3 funded by National Civil Protection Department and National Institute of Geophysics and Vulcanology - Grant, 2004-2006.

Edited by: M. Contadakis

Reviewed by: 3 anonymous referees 


\section{References}

Arias, A.: A measure of earthquake intensity, in: Seismic Design for Nuclear Power Plants, edited by: Hansen, R. J., MIT Press, Cambridge Massachusetts, USA 438-483, 1970.

Bonamassa, O. and Vidale, J. E.: Directional site resonances observed from aftershocks of the 18 October 1989 Loma Prieta earthquake, Bull. Seism. Soc. Am., 81, 1945-1957, 1991.

Bonnefoy-Claudet, S., Cotton, F., and Bard, P.-Y.: The nature of seismic noise wavefield and its implications for site effects studies - A literature review, Earth. Sci. Rev., 79, 205-227, 2006a.

Bonnefoy-Claudet, S., Cornou, C., Bard, P.-Y., Cotton, F., Moczo, P., Kristek, J., and Fäh, D.: H/V ratio: a tool for site effects evaluation - Results from 1D noise simulations, Geophys. J. Int., 167, 827-837, 2006b.

Chávez-García, F. J., Sánchez, L. R., and Hatzfeld, D.: Topographic site effects and HVSR, A comparison between observations and theory, Bull. Seism. Soc. Am., 86, 1559-1573, 1996.

Del Gaudio, V. and Wasowski, J.: Directivity of slope dynamic response to seismic shaking, Geophys. Res. Lett., 34, L12301, doi:10.1029/2007GL029842, 2007.

Gallipoli, M. R. and Mucciarelli, M.: Effetti direzionali in registrazioni sismometriche in aree in frana e bordi di bacino, Extended Abstracts of XXVI G. N. G. T. S. Conference, Rome, 13-15 November 2007, last accessed February 2008 as http://www2.ogs.trieste.it/gngts/gngts/convegniprecedenti/2007/ riassunti/tema-2/2-sess-2/22-gall.pdf, 2007.

Gruppo di Lavoro: "Mappa della Pericolosità Sismica": Redazione della mappa di pericolosità sismica prevista dall' Ordinanza PCM 3274 del 20 marzo 2003, Rapporto Conclusivo per il Dipartimento della Protezione Civile, INGV, Milano-Roma, Italy, 65 pp. e 5 appendici, April 2004.

Guillier, B., Atakan, K., Chatelain, J.-L., Havskov, J., Ohrnberger, M., Cara, F., Duval, A.-M., Zacharopoulos, S., and Teves-Costa, P.: The SESAME Team: Influence of instruments on the H/V spectral ratios of ambient vibrations, Bull. Earthq. Eng., 6, 3-31, doi.:10.1007/s10518-007-9039-0, 2008.
Lermo, J. and Chávez-García, F. J.: Site effect evaluation using spectral ratios with only one station, Bull. Seism. Soc. Am., 83, 1574-1594, 1993.

Martino, S., Minutolo, A., Paciello, A., Rovelli, A., Scarascia Mugnozza, G., and Verrubbi, V.: Evidence of amplification effects in fault zone related to rock mass jointing, Nat. Hazards, 39, 419449, 2006.

Mucciarelli, M.: Reliability and applicability range of the Nakamura's technique, J. Earthq. Eng., 2(4), 625-638, 1998.

Nakamura, Y.: A method for dynamic characteristics estimation of subsurface using microtremors on the ground surface, Quarterly Report Railway Tech. Res. Inst., 30, 25-30, 1989.

Shakal, A. F. and Ragsdale, J. T.: Acceleration, velocity and displacement noise analysis for the CSMIP accelerogram digitization system, in: Proceedings 8th World Conf. Earthquake Engineering, 2, 111-118, 1984.

Spudich, P., Hellweg, M., and Lee, W. H. K.: Directional topographic site response at Tarzana observed in aftershocks of the 1994 Northridge, California, earthquake: implications for mainshock motions, Bull. Seism. Soc. Am., 86(1B), S193-S208, 1996.

Vidale, J. E., Bonamassa, O., and Houston, H.: Directional site resonances observed from the 1 October 1987 Whittier Narrows, California, earthquake and the 4 October aftershock, Earthq. Spectra, 7, 107-125, 1991.

Xu, Z., Schwartz, S. Y., and Lay T.: Seismic wave-field observations at a dense, small-aperture array located on a landslide in the Santa Cruz Mountains, California, Bull. Seism. Soc. Am., 86(3), 655-669.

Wasowski, J. and Del Gaudio, V.: Evaluating seismically induced mass movement hazard in Caramanico Terme (Italy), Eng. Geol., 58 (3-4), 291-311, 2000. 